\title{
Assessment of the Determinants of Healthy Ageing among the Rural Elderly of North-Eastern Nigeria
}

\author{
Babatunji Abayomi Omotara1, Shuaibu Jauro Yahya', Zara Wudiri', Mary Olubisi Amodu1, \\ John Samson Bimba1', Jasper Unyime ${ }^{2}$ \\ ${ }^{1}$ Department of Community Medicine, University of Maiduguri, Maiduguri, Nigeria \\ ${ }^{2}$ Department of Physiotherapy, University of Maiduguri, Maiduguri, Nigeria \\ Email: atunjeba@yahoo.com
}

Received 11 May 2015; accepted 23 June 2015; published 26 June 2015

Copyright (C) 2015 by authors and Scientific Research Publishing Inc.

This work is licensed under the Creative Commons Attribution International License (CC BY). http://creativecommons.org/licenses/by/4.0/

\section{(c) (7) Open Access}

\begin{abstract}
Healthy ageing is a lifelong process optimizing opportunities for improving and preserving health and physical, social and mental wellness, independence, quality of life and enhancing successful life-course transition. In Sub-Saharan Africa, it is estimated that the number of elderly persons will rise from about $\mathbf{3 7 . 1}$ million in 2005 to 155.4 million in 2050 . The elderly population in Nigeria is estimated at 4 percent and is expected to triple by the year 2020 . The increasing number of the older population will increase the burden on the health resources. The objective of this study was to evaluate the determinants of healthy ageing among rural elderly in northern Nigeria in order to promote those that have positive correlation with healthy aging. A cross sectional descriptive study was conducted among 1600 rural elderly aged $\geq 60$ years using interviewer administered semi-structured questionnaire between June and July, 2011. Majority (53.8\%) are 60 - 64 years, $24.6 \%>69$ years, $72.4 \%$ are males while most are Muslims $(85.6 \%)$ and $81.4 \%$ are still married. Most are farmers (48.9\%) while $73.6 \%$ have no formal education. 85.3\% earn less than $\$ 100$ monthly while $\mathbf{4 7 . 6 \%}$ have no income. $\mathbf{9 3 . 5 \%}$ do not take alcohol, $\mathbf{9 2 . 1 \%}$ do not smoke and $\mathbf{8 9 . 8 \%}$ are physically active. $\mathbf{8 3 . 1 \%}$ have normal blood pressure (on examination), $88.3 \%$ normal blood glucose level (on examination). Diet, no smoking, high physical activity and adequate sleep are positively correlated with healthy aging $(p<0.05)$. Good health practices and family support should be sustained while special care for the aged should be established by the government.
\end{abstract}

\section{Keywords}

Ageing, Rural Areas, Nigeria

How to cite this paper: Omotara, B.A., Yahya, S.J., Wudiri, Z., Amodu, M.O., Bimba, J.S. and Unyime, J. (2015) Assessment of the Determinants of Healthy Ageing among the Rural Elderly of North-Eastern Nigeria. Health, 7, 754-764. 


\section{Introduction}

Ageing is an inevitable, natural process that comes with its concomitant health problems which need to be addressed because healthy ageing is necessary for economic and national growth and development. The inevitability of ageing and the fear of dying have haunted the human race and it has been a human dream to retard ageing and defy death [1]. Healthy ageing is a lifelong process optimizing opportunities for improving and preserving health and physical, social and mental wellness, independence, quality of life and enhancing successful lifecourse transitions [2]. In Sub-Saharan Africa, it is estimated that the number of elderly persons will rise from about 37.1 million in 2005 to 155.4 million in 2050. The 20th century transition to lower fertility and mortality ignited an unprecedented growth in the numbers and percentages of elderly. That growth will accelerate in the next century. There will be more than 1 billion people aged 60 and older by 2025, and 2 billion by 2050. Three fourths of these will live in the less developed world [3]. The elderly population in Nigeria is estimated at 4 percent and is expected to triple by the year 2020 [4]. The World Health Organization (WHO) defines elderly persons as those aged 65 years and older. However, in Nigeria, anyone 60 years and older is regarded an elderly person [4]. The well-recognized increase in the population of the elderly who have chronic disease and disability has led to an unprecedented burden on the economy for health care spending and manpower planning. Given the prevailing decrease in the economy of most developed countries, it is imperative that promoting practices that enhance healthy ageing would be one of the best solutions to bridging the gap between the increasing need for health care among the elderly and the dwindling available resources.

WHO defines health as a state of complete physical, mental and social well-being and not merely the absence of disease or infirmity [5]. Health can also be regarded as a dynamic balance in which an individual or a group has the capacity to cope with all circumstances of living at an optimum level [6]. The slope of decline in human health is largely determined by external factors throughout the life course. The natural decline in cardiac or respiratory function, for example, can be accelerated by factors such as smoking and air pollution leaving the individual with lower functional capacity than would normally be expected at a particular age. Health in older age is therefore to a large extent a reflection of the living circumstances and actions of the individual during the entire life span [7].

The objective of this study was to identify the determinants of healthy ageing among the elderly in northeastern Nigeria.

\section{Methods}

\subsection{Study Approach and Setting}

This is a cross sectional descriptive community based study which was conducted among 1600 elderly men and women aged 60 years and above recruited from 20 villages in four rural local government areas (LGAs) from two states (Borno and Adamawa) in north-eastern Nigeria. Borno and Adamawa states are contiguous and located in the semi-arid and savannah regions of Nigeria. Borno state has 27 LGAs while Adamawa has 21. The four LGAs (Konduga, Bama, Gwoza and Madagali) involved in the study are those used by the College of Medical Sciences of the University of Maiduguri for its community based medical education for her medical students as described by Omotara et al. [8]. The four LGAs have a combined population of 837,689 (2006 National Census) [9] with almost equal male and female and the elderly 60 years and above constitute $5.2 \%$ of the population.

Farming, trading, fishing and government work are the major occupation of the people. Literacy level is less than $20 \%$ among both male and female with a further drop among female. Two predominant seasons, dry and rainy are characteristics of both states. They are also both bordered by the Republic of Cameroun, while Borno is in addition bordered by the Republics of Chad and Niger. Majority are Muslim but Adamawa has a higher proportion of Christians.

\subsection{Participants}

Respondents 60 years and above (male and female) were recruited using the neighbourhood method where the community leader was involved in their identification. Informed consent was obtained from each respondent prior to the administration of the questionnaire. Participation in the study was purely voluntary and respondents were interviewed and examined in the comfort of their homes. Approval was obtained from the IRB of the Uni- 
versity of Maiduguri prior to the conduct of the study.

\subsection{Data Collection}

A 79 item questionnaire/profoma was used to obtain information from the respondents by four groups of final year medical students (each group comprised of 6 students) during the 8 week mandatory community-based posting in the communities. However, the data was collected over a six week period between June and July, 2011.

The profoma was in six sections; socio-demographic, life style factors, psychosocial factors, health status and medical factors, anthropometric measurements including blood pressure, urinalysis and eye examination.

Blood pressure of each individual was taken on two different occasions to make diagnosisusing mercury sphygmomanometer (Accuson, Germany) [10], urine specimens were taken to determine glucose level, haematuria and proteinuria using multistick (combostik, S. Korea). In addition anthropometric measurement was taken for each respondent to determine the body mass index (BMI) [11].

\subsection{Data Analysis}

The data was analysed using SPSS v.16.0 for frequencies and percentages, chi square test for association between variables and stepwise regression to test for synergistic relationship of factors that could be associated with healthy aging was also used.

\section{Results}

Table 1 shows the sociodemographic characteristics by age, gender, religion, marital status, occupation and level of education. A total of 1600 elderly aged 60 years and above were recruited for the study out of which 53\% were 60 to 64 years, $72.4 \%$ males and $85.6 \%$ were Muslim. Majority $81.6 \%$ were still married, $48.9 \%$ were farmers while 73.6\% had no formal education. Majority 85.3\% earn less than \$100 (N16000) monthly, 73.6\% did not have medical check-up in the last 12 months preceding the study while only $26.4 \%$ had monthly, quarterly and annual medical check-up.

Table 2 shows the prevalence of chronic medical conditions as reported by the respondents. Only 308 (19.3\%) reported that they were hypertensive out of which 221 (71.8\%) were on antihypertensive medication and 107 (6.7\%) reported to be diabetic out of which 89 (83.2\%) were on medication. On examination, 270 (16.9\%) were found to be hypertensive and 188 (11.8\%) were diabetic. Of the 270 diagnosed to be hypertensive 169 (62.6\%) were newly diagnosed while the remaining were those who had hypertension but was not controlled. Of the 188 diagnosed to be diabetic 142 (75.5\%) were newly diagnosed while the remaining were those whose diabetes were not controlled. There was no significant gender disparity in both conditions.

Slightly more than half $53.4 \%$ reported to have chronic joint pains which shows no significant gender disparity, however, $23.4 \%$ of them use walking aid.

Only $27.6 \%$ had urinary problems with a female/male ratio of 1 to 3 .

Less than half $(46.8 \%)$ reported to have eye problems. On examination $2.5 \%$ were found to have corneal opacity, $4.9 \%$ cataract, $1 \%$ ptosis, $0.4 \%$ ectropium, $0.6 \%$ entropium and others $0.7 \%$.

Table 3 shows the various psychosocial factors associated with healthy ageing among our respondents. Majority $51.2 \%$ did not have any bad experience (stressor) that was still bothering them at the time of study, while $24.8 \%$ had death of a loved one, and $14.2 \%$ had other bad experiences such as robbery and loss of property to fire.

Majority (43.2\%) had social support from children, $28.1 \%$ from wife and children, $25.8 \%$ from wife while a very few had support from husband and other sources, $1.7 \%$ and $1.2 \%$ respectively.

Children were the major source of help with house chores (36.3\%) wife $32.2 \%$ while $25.1 \%$ carried them out by themselves.

Table 4 shows the distribution of lifestyle factors among the respondents. Majority (92.1\%) do not smoke, 89.8\% engage in physical activity while $93.5 \%$ have more than 8 hours of sleep a day. Majority (92.8\%) are on mainly carbohydrate diet while only $2.6 \%, 3.9 \%$ are on mainly protein and mainly carbohydrate and protein diet respectively

Table 5 shows the linear regression of the determinants of aging. Diet, non-smoking, physical activity and 
Table 1. Sociodemographic characteristics of the elderly in north-eastern Nigeria.

\begin{tabular}{|c|c|c|}
\hline Characteristics & No. & $(\%)$ \\
\hline \multicolumn{3}{|l|}{ Age } \\
\hline $60-64$ years & 860 & $(53.8)$ \\
\hline $65-69$ years & 347 & $(21.7)$ \\
\hline$>69$ years & 393 & $(24.6)$ \\
\hline Total & 1600 & (100.0) \\
\hline \multicolumn{3}{|l|}{ Gender } \\
\hline Male & 1158 & (72.4) \\
\hline Female & 442 & $(27.6)$ \\
\hline Total & 1600 & (100.0) \\
\hline \multicolumn{3}{|l|}{ Religion } \\
\hline Islam & 1370 & $(85.6)$ \\
\hline Christian & 214 & (13.4) \\
\hline Traditional & 16 & $(1.0)$ \\
\hline Total & 1600 & (100.0) \\
\hline \multicolumn{3}{|l|}{ Marital status } \\
\hline Married & 1303 & $(81.4)$ \\
\hline Divorced & 35 & $(2.2)$ \\
\hline Widow/widower & 256 & $(16.0)$ \\
\hline Single & 6 & $(0.4)$ \\
\hline Total & 1600 & (100.0) \\
\hline \multicolumn{3}{|l|}{ Occupation } \\
\hline Farmer & 783 & $(48.9)$ \\
\hline Civil servant & 320 & $(20.0)$ \\
\hline Fisherman & 52 & $(3.2)$ \\
\hline Trader & 136 & $(8.5)$ \\
\hline Herdsman & 40 & $(2.5)$ \\
\hline Labourer & 15 & $(0.9)$ \\
\hline Hunter & 4 & $(0.2)$ \\
\hline Others & 250 & $(15.6)$ \\
\hline Total & 1600 & (100.0) \\
\hline \multicolumn{3}{|l|}{ Monthly income } \\
\hline$<\mathrm{N} 5000$ & 766 & $(47.9)$ \\
\hline N5000 - N10,000 & 372 & $(23.2)$ \\
\hline $\mathrm{N} 10,000$ - N15,000 & 227 & $(14.2)$ \\
\hline$>\mathrm{N} 15,000$ & 235 & $(14.7)$ \\
\hline Total & 1600 & (100.0) \\
\hline \multicolumn{3}{|l|}{ Level of education } \\
\hline None & 543 & (33.9) \\
\hline Quranic & 635 & $(39.7)$ \\
\hline Primary & 157 & $(9.8)$ \\
\hline Secondary & 129 & $(8.1)$ \\
\hline Tertiary & 136 & $(8.5)$ \\
\hline Total & 1600 & (100.0) \\
\hline \multicolumn{3}{|c|}{ Frequency of medical check up } \\
\hline None & 1178 & $(73.6)$ \\
\hline Monthly & 240 & $(15.0)$ \\
\hline Quarterly & 78 & $(4.9)$ \\
\hline Annually & 104 & $(6.5)$ \\
\hline Total & 1600 & $(\mathbf{1 0 0 . 0})$ \\
\hline
\end{tabular}


Table 2. Prevalence of chronic medical conditions amongst the elderly in north-eastern Nigeria.

\begin{tabular}{ccc}
\hline Variable $^{\text {Hypertension }}{ }^{\mathbf{a}}$ & No. & $\mathbf{( \% )}$ \\
Yes & 308 & $(19.3)$ \\
No & 1292 & $(80.7)$ \\
Total & $\mathbf{1 6 0 0}$ & $(\mathbf{1 0 0 . 0})$ \\
Diabetes mellitus $^{\mathbf{b}}$ & & \\
Yes & 107 & $(6.7)$ \\
No & 1493 & $(93.3)$ \\
Total & $\mathbf{1 6 0 0}$ & $(\mathbf{1 0 0 . 0})$ \\
Chronic pains & & \\
Yes & 1032 & $(64.5)$ \\
No & 746 & $(35.5)$ \\
Total & 1600 & $(100.0)$ \\
Walking aid & & \\
Yes & 242 & $(23.4)$ \\
No & 790 & $(76.6)$ \\
Total & 1032 & $(100.0)$ \\
Urinary problems & & \\
Yes & 442 & $(27.6)$ \\
No & 1158 & $(72.4)$ \\
Total & 1600 & $(100.0)$ \\
Eye problems & & \\
Yes & 1134 & $(70.9)$ \\
No & 851 & $(20.1)$ \\
Total & 1600 & $(100.0)$ \\
\hline
\end{tabular}

${ }^{a}$ On examination, 270 (16.9\%) were found to be hypertensive, out of which 169 were newly diagnosed, 221 of the 308 who reported to be hypertensive said they were on medication. ${ }^{\mathrm{b}} \mathrm{On}$ examination, $188(11.8 \%)$ were found to be diabetic of which 142 were newly diagnosed, 89 of the 107 who reported to be diabetic said they were on medication. 184 (11.5\%) had hypertension and diabetes, 97 (6.06) had hypertension, diabetes and eye problem and 72 (4.5\%) had hypertension, diabetes, eye problem and chronic body pains.

Table 3. Psychosocial factors associated with healthy ageing among the elderly in northeastern Nigeria.

\begin{tabular}{ccc}
\hline Variable & No. & $\mathbf{( \% )}$ \\
Stressors & 397 & $(24.8)$ \\
Death & 80 & $(5.0)$ \\
Bankruptcy & 75 & $(4.7)$ \\
Accidents & 228 & $(14.2)$ \\
Others & 820 & $(51.2)$ \\
None & $\mathbf{1 6 0 0}$ & $\mathbf{( 1 0 0 . 0 )}$ \\
Total & & \\
Social supports & 413 & $(25.8)$ \\
Wife & 692 & $(43.2)$ \\
Children & 450 & $(28.1)$ \\
Wife and children & 27 & $(1.7)$ \\
Husband & 18 & $(1.2)$ \\
Others & $\mathbf{1 6 0 0}$ & $(\mathbf{1 0 0 . 0})$ \\
Total & & \\
Self & 401 & $(25.1)$ \\
Wife & 515 & $(32.2)$ \\
Children & 581 & $(36.3)$ \\
Others & 103 & $(6.4)$ \\
Total & $\mathbf{1 6 0 0}$ & $\mathbf{( 1 0 0 . 0 )}$ \\
\hline
\end{tabular}


Table 4. The distribution of lifestyle factors among the ageing population in north-eastern Nigeria.

\begin{tabular}{|c|c|c|c|}
\hline Variable & Response & No & (\%) \\
\hline \multirow[t]{3}{*}{ Smoking } & Yes & 127 & 7.9 \\
\hline & No & 1473 & 92.1 \\
\hline & & 1600 & 100.0 \\
\hline \multirow[t]{3}{*}{ Physical activity } & Yes & 1437 & 89.8 \\
\hline & No & 163 & 10.2 \\
\hline & & 1600 & 100.0 \\
\hline \multirow[t]{3}{*}{ Alcohol } & Yes & 104 & 6.5 \\
\hline & No & 1496 & 93.5 \\
\hline & & 1600 & 100.0 \\
\hline \multirow[t]{3}{*}{ Duration of sleep } & $<8$ hrs/day & 292 & 18.3 \\
\hline & $>8$ hrs/day & 1308 & 81.7 \\
\hline & & 1600 & 100.0 \\
\hline \multirow[t]{5}{*}{ Diet } & Carbohydrate & 1484 & 92.8 \\
\hline & Protein & 42 & 2.6 \\
\hline & Carbohydrate/protein & 63 & 3.9 \\
\hline & Others & 11 & 0.7 \\
\hline & & 1600 & 100.0 \\
\hline
\end{tabular}

Table 5. Linear regressions of the determinant of healthy ageing among the elderly (age as the dependent variable) in northeastern Nigeria.

\begin{tabular}{lccc}
\hline \multicolumn{1}{c}{ Lifestyle factors } & $\mathbf{R}^{2}$ & p-value & Significance \\
\hline 1. Diet & 0.051 & 0.000 & Yes \\
2. Alcohol consumption & 0.005 & 0.239 & No \\
3. Cigarette smoking & 0.059 & 0.043 & Yes \\
4. Physical activity & 0.041 & 0.034 & Yes \\
5. Duration of sleep & 0.098 & 0.047 & Yes \\
Psychosocial factors & & & No \\
6. Stressful events & 0.017 & 0.016 & Yes \\
7. Social support & 0.089 & 0.122 & Yes \\
8. Family history of long life & 0.065 & 0.001 & \\
Socio-economic factor & & 0.004 & \\
9. Level of education & 0.058 & & Yes \\
Medical factor & & 0.002 & \\
10. Chronic medical condition, i.e. & & & \\
Hypertension, diabetes & 0.079 & & \\
\hline
\end{tabular}


duration of sleep were found to be positively associated with healthy aging while non-alcohol consumption was not $\left(R^{2}=0.005, p=0.29\right)$.

Table 6 shows the result of stepwise regression on association between various combinations of lifestyle factors and association between various combinations of psychosocial factors as determinants of healthy ageing.

Table 6. Step wise multiple regression of lifestyle and psychosocial factors of healthy ageing in the elderly of north-eastern Nigeria.

\begin{tabular}{|c|c|c|c|}
\hline Variables & $\mathbf{R}^{2}$-value & p-value & Significance \\
\hline \multicolumn{4}{|l|}{ Association between two lifestyle factors } \\
\hline 1. Diet and alcohol & 0.044 & 0.001 & Yes \\
\hline 2. Diet and cigarette smoking & 0.057 & 0.022 & Yes \\
\hline 3. Diet and physical activity & 0.410 & 0.000 & Yes \\
\hline 4. Diet and duration of sleep & 0.002 & 0.958 & No \\
\hline 5. Cigarette smoking and physical activity & 0.001 & 0.175 & No \\
\hline 6. Cigarette smoking and duration of sleep & 0.053 & 0.034 & Yes \\
\hline 7. Physical activity and duration of sleep & 0.204 & 0.000 & Yes \\
\hline \multicolumn{4}{|l|}{ Association between three lifestyle factors } \\
\hline 1. Diet, alcohol consumption and cigarette smoking & 0.001 & 0.633 & No \\
\hline 2. Diet, alcohol consumption and physical activity & 0.237 & 0.000 & Yes \\
\hline 3. Diet, alcohol consumption and duration of sleep & 0.244 & 0.000 & Yes \\
\hline 4. Alcohol consumption, physical activity and duration of sleep & 0.026 & 0.024 & Yes \\
\hline 5. Cigarette smoking, diet and physical activity & 0.076 & 0.001 & Yes \\
\hline 6. Cigarette smoking, diet and duration of sleep & 0.053 & 0.032 & Yes \\
\hline 7. Cigarette smoking, physical activity and duration of sleep & 0.034 & 0.003 & Yes \\
\hline 8. Physical activity, diet and duration of sleep & 0.042 & 0.000 & Yes \\
\hline \multicolumn{4}{|l|}{ Association between four and five lifestyle factors } \\
\hline 1. Diet, alcohol consumption, cigarette smoking and physical activity & 0.049 & 0.000 & Yes \\
\hline \multicolumn{4}{|l|}{ 2. Alcohol consumption, cigarette smoking, } \\
\hline 3. Physical activity and duration of sleep & 0.043 & 0.008 & Yes \\
\hline \multicolumn{4}{|l|}{ 4. Cigarette smoking, physical activity, } \\
\hline 5. Duration of sleep and diet & 0.049 & 0.000 & Yes \\
\hline 6. Physical activity, duration of sleep, diet and alcohol consumption & 0.041 & 0.001 & Yes \\
\hline 7. Duration of sleep, diet, alcohol consumption and cigarette smoking & 0.003 & 0.022 & Yes \\
\hline \multicolumn{4}{|l|}{ 8. Diet, alcohol consumption, cigarette smoking, } \\
\hline 9. Physical activity and duration of sleep & 0.041 & 0.001 & Yes \\
\hline \multicolumn{4}{|l|}{ Association between various psychosocial factors } \\
\hline 1. Social support and family history of long life & 0.011 & 0.050 & Yes \\
\hline $\begin{array}{l}\text { 2. Family history of long life and stressful events stressful event, } \\
\text { social support and family }\end{array}$ & 0.024 & 0.000 & Yes \\
\hline 3. History of long life & 0.024 & 0.004 & Yes \\
\hline
\end{tabular}


Diet in combination with alcohol consumption $\left(\mathrm{R}^{2}=0.044, \mathrm{p}=0.001\right)$, cigarette smoking $\left(\mathrm{R}^{2}=0.057, \mathrm{p}=0.022\right)$ and physical activity were significantly associated with healthy ageing while no significance was observed in combination with duration of sleep $\left(\mathrm{R}^{2}=0.002, \mathrm{p}=0.958\right)$. Combination of cigarette smoking with physical activity was not significantly associated with healthy ageing while combination of duration of sleep with cigarette smoking and physical activity were significantly associated with healthy ageing. Combination of three life styles were significantly related to healthy ageing except the combination of diet, alcohol and cigarette smoking $\left(\mathrm{R}^{2}=\right.$ $0.001, p=0.633$ ). Combination of four and five life style factors were all significantly associated with healthy ageing while combination of the various psychosocial support were also significantly associated with healthy aging among our study population.

\section{Discussion}

The results of this study show that 1134 (70.9\%) had at least one of the major chronic health problems (hypertension, diabetes, eye and chronic body pains) while 72 (4.5\%) had all the four comorbidities, 97 (6.06\%) had hypertension, diabetes and eye conditions and $184(11.5 \%)$ had hypertension and diabetes. This is perhaps not surprising as majority of them reported good lifestyle habits such as not smoking (92.1\%), no alcohol consumption (93.5\%), engaging in physical activity (89.8\%) and having more than 8 hours of sleep a day (81.7\%). Poor sleeping can lead to a number of health problems. Older adults who have poor night time sleep are more likely to have depressed mood, attention and memory problems, excessive daytime sleepiness; more night time falls, and use more over the counter or prescription sleep aids. Poor sleep is also associated with a poorer quality of life. Sleep needs changes over a person's life time. Children and adolescents need more sleep than adults. Interestingly, older adults need about the same amount of sleep as young adult—seven to nine hours of sleep per night [12]. Caughey et al. [13] reported a prevalence of comorbidity of $80 \%$ of elderly population having three or more chronic conditions. Naughton et al. [14] reported that $86 \%$ of the elderly population in their study had experienced at least one of nine chronic conditions identified in which cardiovascular conditions were the highest costing disease group. Almost 75\% of the elderly (aged 65 and over) have at least one chronic illness, while at least 50\% have at least two chronic illnesses [15]. Chronic conditions can lead to immediate disabilities, such as hip fractures and stroke, as well as progressive disability that slowly erode the ability of the elderly people to care for themselves [16]. In our study $15.1 \%$ reported using walking aid while $8.5 \%$ were blind in both eyes and $20.8 \%$ in one eye. Abdulraheem and Abdulrahman [17] reported 14.6\% blindness among elderly seen in a tertiary health institution in North-central Nigeria.

A higher level physical activity has been associated with increased survival [18], a delay in the progression of disability [19], and loss of functional ability [20] improved balance and strength [21] [22], reduced incidence of falls [23] as well as higher quality of life [24] [25].

A high-quality diet, non-smoking and physical activity were related to survival in elderly Europeans aged 70 75 years [26]. Smoking has been associated with increased risk of mortality before age 90 years, and was associated with hypertension, diabetes, and obesity. Modifiable healthy behaviors during early elderly years, including smoking, abstinence, weight management, blood pressure control, and regular exercise are associated not only with enhanced life span in men but also with good health and function during older years [27]. The limitation of our study was the inability to adequately determine the dietary intake of our respondents. As it is often with nutritional research, determination of dietary intake has always presented methodological challenges. We based our dietary intake on a 24 hour dietary recall. Determination of caloric intake is often not possible in most cases especially in rural areas where the study was conducted. Majority of our respondents were on carbohydrate diet which usually comprise of millet, sorghum, maize and rice usually served with vegetable, fish and poultry or beef. Household food sufficiency is often high in most rural areas of Nigeria as most inhabitants are farmers. However food storage often poses challenges during the dry season which may lead to short period of near insufficiency in some areas especially in arid region. Body Mass Index (BMI) is a good measure of nutritional status of an individual. Majority (44.5\%) of our elderly have normal BMI (18.5 - 24.9) while 29\% are underweight and $26.2 \%$ over weight of which $8.4 \%$ are obese. There is controversy on the usefulness of BMI as a true indicator of body fat in the elderly [28]. Many older persons with low or normal BMI may have disease related weight loss. Weight loss in elderly has been shown to be associated with negative health outcomes [29]. Measurement of weight change over a period of time is considered more realistic [28]. Majority (73.6\%) of our elderly had no medical check-up in the past 12 months preceding the study, 15\% had monthly check-up, $4.9 \%$ 
quarterly while $6.5 \%$ had annual check-up. This is considered very unfortunate and is in consonance with the weak health care system in less developed countries.

The major psychosocial stressor reported to have had a major impact on the health of the respondents in our study was death of a loved one (24.8\%) while social support was majorly provided by children (43.2\%). This reflects the strong cultural practice in this part of the world. Both nuclear and extended family system is still very much in existence in most of our communities especially in the rural areas. Wife and combination of wife and children $(25.8 \%, 28.1 \%)$ respectively were also reported which is in support of the strong family tie. One quarter (25.1\%) were able to carry out various house chores by themselves while the rest were assisted by other members of the nuclear family. Generally in Nigeria, there is an observable progressive shift in function away from the traditional family. Traditional functions of the family like care and social support to older family members have gradually decreased in recent past due to economic problems, migration and influence by foreign culture. Family members however are unable to effectively cope with the challenges of daily living. Emphasis is now on the nuclear family of "me, my wife and my children" at the expense of other members of the wider family network, especially the older ones who look to the younger generation to provide them with economic security in old age. The government does not provide social security for older persons. These changes in family structure in Nigeria, though more pronounced in urban areas, have caused gradual disintegration of the extended family and of the communal sense of living in many Nigerian societies [30]. Suffering from either depression, loneliness or feeling of neglect was reported among elderly by Kishore et al. [31] while Prakash et al. [32] reported much more psychosocial problems in their study subjects. Even though our study shows good evidence of family support for the elderly, there is little evidence of government support. It has been observed that less developed countries face the greatest challenge from population ageing [33]. Most of these countries are not equipped to meet the financial, health and housing needs of older people. Many have minimal public pension programs (Nigeria began contributory pension in 2004 only for government workers) for the elderly and many people entering retirement age in these countries over the next 15 years will have little income from private pensions or savings. Policy makers in many less developed countries have relied on families to support ageing family members [33]. It is pertinent to note that traditional support systems are deteriorating in many areas just as the need for support is growing. Effort to formulate and implement a national policy on the care and well-being of the elderly in Nigeria has not been successful. The proposed draft was completed in March 2004, yet to date it has not been ratified by the Federal Executive Council (FEC) the highest law making body. Law makers are neither sufficiently sensitized to the scope, nature or seriousness of older people's problems, nor to the broad economic and social development implications of leaving these problems unaddressed in the context of rapid population ageing [34].

\section{Conclusions}

Our study reveals that diet, smoking, alcohol consumption and physical activity are significantly associated with healthy ageing among our study population. In addition, combinations of this factor or the lack of it was also associated with healthy ageing. Majority of our respondents did not smoke, take alcohol and were mainly on carbohydrate diet. Prevalence of hypertension, diabetes and other ailments was reasonably modest compared with those reported in other studies. However, eye problem of one type or the other had the highest prevalence among the study population. Family support especially among nuclear family seems to still be in place. The fact that majority did not have medical examination in the past 12 months is an indication of the poor and inadequate health care system which the three tiers of government (local, state and federal) need to seriously address. One hundred and forty-two (8.9\%) were diagnosed with diabetes and 169 (10.6\%) were diagnosed with hypertension during the study; these are cases which should have be diagnosed if the health system is properly in place. It also indicates that there is a need for improvement in the health seeking behavior of the community. These two should be done simultaneously, that is: improvement in the health care system and creation for awareness on the importance of regular medical check-up for elderly.

The need for the Nigerian government to take the issue of care of the elderly with all the seriousness it deserves has been sufficiently made by the growing number of elderly due to reduced fertility and increasing life expectancy. Older people's lives are characterized by growing inadequacies in customary family supports, social exclusion and non-existent social security targeted at them, thus being vulnerable to poverty and diseases. 


\section{Acknowledgements}

We acknowledge the groups of final year medical students for collecting the data, the Primary Health Care departments of the four LGAs and the community leaders of the various communities for their cooperation during the period of the study.

\section{References}

[1] Sainani, G.S. and Sainani, R. (2005) Retarding Ageing-Healthy Aging. Medicine Updates, 173, 854-855.

[2] Peel, N.M., McClure, R.J. and Bartlett, H.P. (2005) Behavioral Determinants of Healthy Ageing. American Journal of Preventive Medicine, 28, 298-304. http://dx.doi.org/10.1016/j.amepre.2004.12.002

[3] Gelberd, A., Haub, C. and Kent, M. (1999) World Population beyond Six Billion. Population Bulletin, March, 38.

[4] (2008) Nigerian Demographic and Health Survey (NDHS).

[5] WHO (2011) Definition of Health. http://www.who.int/about/definition/en/print.html

[6] Bass, S.A. (2006) Gerontological Theory: The Search for the Holy Grail. Gerontology, 46, 139-144. http://dx.doi.org/10.1093/geront/46.1.139

[7] Kalache, A. and Kickbusch, I. (1997) A Global Strategy for Healthy Ageing. World Health, 4, 4-5.

[8] Omotara, B.A., Padonu, M.K.O., Bassi, A.P. and Amodu, M.O. (1992) Community-Based Medical Education (CBME): University of Maiduguri Experience. Annals of Community-Oriented Education, 5, 41-46.

[9] (2006) Federal Republic of Nigeria National Census.

[10] Timmis, A. (2007) Cardiovascular System. In: Swash, M. and Glynn, M., Eds., Hutchinson's Clinical Methods, 22nd Edition, Saunders Elsevier, Philadelphia, 77. http://dx.doi.org/10.1016/b978-0-7020-2799-4.50012-1

[11] Powell-Tuck, J. (2007) Nutritional Assessment. In: Swash, M. and Glynn, M., Eds., Hutchinson's Clinical Methods, 22nd Edition, Saunders Elsevier, Philadelphia, 45-46.

[12] New York Access to Health (accessed 29 June 2012) Sleep Disorder-Ageing and Sleep. www.noahhealth.org/en/sleep/concern/elderly.html

[13] Naughton, C., Bennett, K. and Feely, J. (2006) Age and Ageing. Oxford Journals, 35, 633-636.

[14] Caughey, G.E., Vitry, A.I., Gilbert, A.L. and Roughead, E.E. (2008) Prevalence of Comorbidity of Chronic Diseases in Australia. BMC Public Health, 8, 221. http://dx.doi.org/10.1186/1471-2458-8-221

[15] Calkins, E., Boult, C., Wagner, E., et al. (1999) New Ways to Care for Older People: Building Systems Based on Evidence. Springer, New York.

[16] Fied, L.P. and Guralnik, J.M. (1997) Disability in Older Adults: Evidence Regarding Significance, Etiology, and Risk. Journal of the American Geriatrics Society, 45, 92-100. http://dx.doi.org/10.1111/j.1532-5415.1997.tb00986.x

[17] Abdulraheem, I.S. and Abdulrahman, A.G. (2008) Morbidity Pattern among the Elderly Population in a Nigerian Tertiary Health Care Institution: Analysis of a Retrospective Study. Nigerian Medical Practitioner, 54, 32-38.

[18] Morgan, K. and Clarke, D. (1997) Customary Physical Activity and Survival in Later Life: A Study in Nottingham, UK. Journal of Epidemiology Community Health, 51, 490-493. http://dx.doi.org/10.1136/jech.51.5.490

[19] Fries, J. (1996) Physical Activity, the Compression of Morbidity, and the Health of the Elderly. Journal of the Royal Society of Medicine, 89, 64-68.

[20] Ho, S.C., Woo, J., Yuen, Y.K., et al. (1997) Predictors of Mobility Decline: The Hong Kong Old-Old Study. The Journals of Gerontology, 25, M356-M362. http://dx.doi.org/10.1093/gerona/52A.6.M356

[21] Wolfson, L., Whipple, R., Derby, C., et al. (1996) Balance and Strength Training in Older Adults: Intervention Gains and Tai Chi Maintenance. Journal of the American Geriatrics Society, 44, 498-506. http://dx.doi.org/10.1111/j.1532-5415.1996.tb01433.x

[22] Wolf, S.L., Barnhart, H.X., Kutner, N.G., et al. (1996) Reducing Frailty and Falls in Older Persons: An Investigation of Tai Chi and Computerized Balance Training. Journal of the American Geriatrics Society, 44, 489-497. http://dx.doi.org/10.1111/j.1532-5415.1996.tb01432.x

[23] Campbell, A.J., Robertson, M.C., Gardner, M.M., et al. (1997) Randomised Controlled Trial of a General Practice Programme of Home Based Exercise to Prevent Falls in Elderly Women. BMJ, 315, 1065-1069. http://dx.doi.org/10.1136/bmj.315.7115.1065

[24] MacRae, P.G., Asplund, L.A., Schnelle, J.F., et al. (1996) A Walking Program for Nursing Home Residents: Effect on Walk Endurance, Physical Activity, Mobility and Quality of Life. Journal of the American Geriatrics Society, 44, 175180. http://dx.doi.org/10.1111/j.1532-5415.1996.tb02435.x 
[25] Ruuskanen, J.M. and Ruoppila, I. (1995) Physical Activity and Psychological Well-Being among People Aged 65 to 84 yr. Age and Ageing, 24, 292-296. http://dx.doi.org/10.1093/ageing/24.4.292

[26] Haveman-Nies, A., De Groot, L.C.P.G.M. and Van Staveren, W.A. (2003) Dietary Quality, Lifestyle Factors and Healthy Ageing in Europe: The SENECA Study. Age and Ageing, 32, 427-434. http://dx.doi.org/10.1093/ageing/32.4.427

[27] Yates, L.B., Djousse, L., Kurth, T., et al. (2008) Exceptional Longevity in Men: Modifiable Factors Associated with Survival and Function to Age 90 Years. Archives of Internal Medicine, 168, 284-290. http://dx.doi.org/10.1001/archinternmed.2007.77

[28] Fuhrman, J. (2011) Disease Proof Health and Nutrition News and Commentary. Excess Weight Is Protective in the Elderly? New Research Says No. Posted on 12 October 2011 by Deana Ferreri, PhD.

[29] Woo, J., Ho, S.C. and Sham, A. (2001) Longitudinal Changes in Body Mass Index and Body Composition over 3 Years and Relationship to Health Outcomes in Hong Kong Chinese Age 70 and Older. Journal of the American Geriatrics Society, 49, 737-746. http://dx.doi.org/10.1046/j.1532-5415.2001.49150.x

[30] Ajomale, O. (2007) Country Report: Ageing in Nigeria-Current State, Social and Economic Implications. In: Hoff, A., Ed., Summer Newsletter 2007 of the Research Committee (RC11) on the Sociology of Ageing of the International Sociological Association (ISA), Oxford Institute of Ageing, Oxford, 15-20.

[31] Kishore, S., Juyal, R., Semwal, J., et al. (2007) Morbidity Profile of Elderly Persons. JK Science, 9, 87-89.

[32] Prakash, R., Choudhary, S.K. and Singh, U.S. (2004) A study of Morbidity Pattern among Geriatric Population in an Urban Area of Udaipur, Rajasthan. Indian Journal of Community Medicine, 29, 35-40.

[33] Holden, C. (1992) New Populations of Old Add to Poor Nations’ Burdens. Science, 273, 46-47.

[34] Asagba, A. (2005) Research and the Formulation and Implementation of Ageing Policy in Africa: The Case of Nigeria. British Society of Gerontology, 15, 39-41. 